\title{
Effects of Real-time Eco-feedback and Organizational Network Dynamics on Energy Efficient Behavior in Commercial Buildings
}

\author{
Rimas Gulbinas \\ Via Fellow, Charles E. Via, Jr. Department of Civil and Environmental Engineering, \\ Virginia Tech, Blacksburg, United States \\ e-mail: rimasg@vt.edu \\ John E. Taylor ${ }^{1}$ \\ Associate Professor, Charles E. Via, Jr. Department of Civil and Environmental Engineering, \\ Virginia Tech, Blacksburg, United States \\ e-mail: jet@vt.edu
}

\begin{abstract}
Commercial buildings account for a significant portion of energy consumption and associated carbon emissions around the world. Consequently, many countries are instituting building energy efficiency policies to mitigate the negative environmental impacts of building operations. As building owners and operators act to address the challenge of increasing energy efficiency, occupant behavior modification programs are growing increasingly popular. Recent advances in energy monitoring and control technologies have enabled the development of eco-feedback systems that collect, process, and relay high resolution, real-time energy consumption information to help building occupants control their energy-use. These systems have extended research into the effects of high resolution eco-feedback on building occupant behavior and energy efficiency from residential to commercial building settings. However, little is understood about how organizational network dynamics impact user-engagement levels with such systems and how these network connections may impact the energy conservation behavior of individuals inside commercial buildings. In this paper, results are presented from a novel 9-week ecofeedback system study which demonstrates that organizational network dynamics can significantly impact energy conservation among commercial building occupants. Furthermore, it is shown that exposure to eco-feedback impacts building occupant energy conservation differently in commercial office buildings than it does in residential buildings.
\end{abstract}

Keywords: Behavior; Commercial Buildings; Eco-feedback; Energy Management;

Organizational Networks; Social Networks

${ }^{1}$ Corresponding author 


\section{Introduction}

Buildings represent a major link between society and the environment and are an essential element in any strategy designed to promote environmental sustainability. In the United States, where humans spend nearly $90 \%$ of their time indoors [1], buildings are responsible for roughly $41 \%$ of all carbon emissions [2]. Without significant interventions, $\mathrm{CO}_{2}$ emissions from US buildings are expected to increase faster than any other sector over the next two decades with commercial building emissions projected to grow the fastest, at 1.8\% each year through 2030 [3]. To combat this alarming projection, the United States has set a federal target of reducing total national greenhouse gas emissions by $80 \%$ by 2050 [4]. As buildings account for approximately $40 \%$ of all US energy consumption [5], one strategy for achieving this ambitious emissions reduction goal is to motivate widespread building-sector energy conservation. This approach has spurred numerous initiatives that promote energy efficiency, including: efficiency rating and certification programs for buildings [6,7] and appliances [8], the establishment of energy data standards and repositories [9], and the development of Building Energy Management System (BEMS) standards [10].

\section{Background}

Acknowledging emissions reduction targets and energy conservation initiatives, researchers have increased efforts to improve building energy efficiency by focusing on the development of technological innovations (insulation, lighting, heating, cooling systems) as well as effective behavioral modification strategies (feedback, goal-setting, information campaigns). However, while technological advancements have benefited both residential and commercial buildings, behavior-based energy conservation research has traditionally focused on residential buildings.

Advances in computing capabilities and data analysis techniques have enabled the development of energy efficiency programs and research studies of unprecedented scale. Following the example of seminal residential energy feedback studies dating back to the late 1970's [11, 12], recent studies have investigated the effects of goal-setting [13, 14], normative comparisons [15, 16], and descriptive and injunctive norms [17] on energy conservation. The results of these studies have spurred the development of utility-scale residential energy feedback programs [18, 19] that have resulted in significant energy savings that have been externally verified with large data sets of size [20]. Furthermore, technological advances have also enabled the development of web-enabled eco-feedback systems that communicate increasingly high-resolution and highfrequency energy-use feedback [21] that building occupants can learn from in order to take action to conserve energy [22].

Eco-feedback systems have facilitated behavior-based energy efficiency studies in single-family buildings as well as multi-tenant complexes and have contributed many insights into how feedback granularity [23, 24], social comparisons and rankings [25, 26, 27], competitions [28], and data representation [29] all impact energy efficient behavior. Furthermore, interactions between users over such systems have also revealed that social network dynamics significantly impact energy conservation [30] and users directly influence one another's energy conservation behavior [31]. Studies enabled by the application of eco-feedback systems, which have even 
been the focus of usability studies [32, 33, 34, 35], continue to garner behavioral, sociological, and psychological insights related to energy conservation. However, despite the quantity of behavior-based research in residential buildings and the fact that eco-systems have been observed to yield significant building-level energy savings ranging from 5-55\% [36], commercial buildings have more slowly adopted eco-feedback technologies as they have become more costeffective.

Advanced eco-feedback systems stand to benefit commercial buildings by empowering building occupants to conserve energy, an effective strategy for achieving significant energy-use reductions as demonstrated by simulation models [37, 38], academic research studies [39, 40] and industry sponsored energy efficiency initiatives [41, 42]. Furthermore, modular ecofeedback systems [43] allow commercial buildings to realize potential energy savings without necessitating intrusive physical building retrofits and equipment upgrades, which are often capital intensive and subject to a split incentive structure in which building owners bear the initial investment costs while commercial tenants benefit from resulting reduced operating costs [44]. As eco-feedback systems have only recently begun to be designed for and utilized in commercial buildings, it is essential to understand how individuals interact with these systems in the presence of organizational and social forces that are often absent in residential settings. Through targeted studies, it is possible to determine the potential of eco-feedback systems to drive energy conservation in commercial buildings and to understand how to optimize the design of such systems to maximize energy savings through behavior-based interventions.

An important first step for determining the energy-savings potential of eco-feedback systems in commercial buildings is to understand how energy feedback can impact behavior in an environment where individuals have no direct financial responsibility regarding their energy-use. Utilizing advanced eco-feedback systems, recent studies have been able to engage commercial building occupants with real-time energy-use feedback while also monitoring changes in their actual energy consumption. One of the first attempts to quantify the effects of individual ecofeedback on conservation behavior in commercial buildings found that such feedback does not necessarily result in sustained energy savings [45]. It should be noted, however, that this study was conducted in a university building in which occupants were comprised of students, researchers, and lecturers. It is therefore necessary to extend eco-feedback research to commercial buildings in a more representative non-university setting where organizational and cultural forces may be more prevalent, as these have been shown to significantly influence individual conservation behavior and attitudes [46].

In this paper, results are presented from an empirical eco-feedback study conducted in a nonuniversity affiliated commercial office building where building occupants were provided with access to energy-use feedback through an advanced eco-feedback system that connects individuals over organizational networks [43]. The study was designed to investigate whether: 1) exposure to individual energy-use feedback leads to a reduction in personal energy-use among commercial building occupants, and 2) organizational network dynamics, e.g. normative pressures, impact commercial building occupant energy consumption. The second research question aims to expand on the results of two prior studies. The first study, in which information 
about energy saving actions was collected and communicated manually, found that employees exposed to comparative group-based feedback adopted more energy saving actions than groups who only received feedback about their own actions [40]. The second study, in which an advanced eco-feedback system was used, found that occupants in a multi-tenant residential building who received social network energy data in addition to their own conserved more energy than individuals who were exposed only to personal energy-use feedback [27]. It is therefore important to understand if the same network and normative effects are observed among commercial building occupants exposed to real-time energy-use feedback. An understanding of how eco-feedback and organizational network dynamics impact energy-use behavior among commercial building occupants can be used to increase the effectiveness of future eco-feedback system designs to realize maximum energy saving potential.

\section{Methodology}

To determine how individual energy feedback and organizational network dynamics may impact energy-efficient behavior among commercial building occupants, a controlled 9 week study (following a 3 week baseline period) involving 98 employees in a non-university affiliated commercial office building was conducted.

\subsection{Study Building}

The study was conducted in a 6-story multi-tenant commercial office building (Fig. 1) located in downtown Denver, CO. The 40,000 square-foot LEED certified building, owned and operated by the Alliance for Sustainable Colorado, was originally built c. 1908. Since then, it has gone through numerous rebuilds and renovations, the most recent of which was completed in 2004 when it underwent major energy-efficiency upgrades.

During the period of the study, approximately 115 full-time employees spanning 27 non-profit organizations occupied the building. The majority of organizations in the building possessed an environmental focus and were already committed to sustainable practices prior to the start of the study. Employees typically occupied the building during regular working hours, from 9:00am to 5:00pm from Monday to Friday. Outside of these regular working hours, the building doors were locked to the general public. Power monitors were installed at each assigned workstation/desk in the building and recorded the total electricity consumption of all connected appliances. Details about the power monitoring devices used are provided in Section 3.4. Typically connected appliances included computers, monitors, space heaters, and electronics chargers. Furthermore, each floor in the building had electrical sub-meters installed, which were present prior to the start of the study.

\subsection{Study Design and Hypotheses}

In order to isolate the impacts of exposure to individual energy-use feedback and organizational network dynamics on energy conservation behavior, participants were placed in groups with different levels of access to energy feedback (additional recruitment details are provided in the following section): 
- The Individual Feedback group (Group A - 47 people): participants in this group received access only to their own current and historical energy-use feedback. Unlike Study Group $B$, individuals could not view the energy-use information of others in their organization and therefore could not make direct comparisons over the eco-feedback system.

- The Organizational Network group (Group B - 29 people): participants in this group received access to individual and group-level current and historical energy-use feedback as well as the energy-use information and self-reported conservation actions of other employees in their organization. Energy data sharing permissions and network connections were pre-populated into the eco-feedback system before the start of the study.

- The Control group (22 people): individuals in this group received no access to energy-use feedback and could not access the eco-feedback system. Energy-use information was still recorded for individuals in this group.

To control for the possibility of social interactions that could potentially confound study results (e.g. sharing energy-use information with participants in other study groups), participants were assigned to groups according to their physical location within the study building and the size of their respective organizations. Study Group A consisted of individuals working for several independent organizations consisting of 1-9 employees, which were distributed over four floors. Study Group B included the two largest organizations in the building, which spanned two floors. Finally, the Control Group consisted of individuals who opted out of receiving feedback and were physically distributed over all floors, in order to mitigate potential energy-use idiosyncrasies related to physical location within the building.

Data collected for individuals in the three groups were used to test two hypotheses:

Hypothesis 1: Individuals with access to only their own, personal energy consumption feedback (Group A) will reduce their average daily energy-use relative to their baseline values and the control group.

Hypothesis 2: Individuals with access to personal energy consumption feedback and that of others in their organizational networks (Group $B)$ will reduce their average daily energy-use relative to their baseline values and the control group.

\subsection{Recruitment}

Approval for a human subjects experiment was obtained from Virginia Tech's Institutional Review Board prior to the recruitment process. During the recruitment period, announcements about the study were made through email messages and in-person interactions with researchers. Participants could sign up in-person or on a Virginia Tech hosted website that also contained detailed information about the study. Recruitment materials emphasized that study participation was optional and that participants could potentially access their own energy-use feedback as well as that of their colleagues, and that their energy-use data might be reciprocally shared among colleagues. Potential environmental benefits associated with study participation were not 
included in recruitment materials. In total, 76 out of approximately 115 full-time employees agreed to participate in the study by receiving and/or sharing energy-use information. Employees who opted-out of the study cited a lack of time, an inability to commit, and concerns over privacy, which have also been raised in other energy feedback studies [47]. Study participants consisted of employees of varying ages, with a higher concentration of young professionals between the ages of 25 and 35 . Slightly more women (62\%) elected to participate than men.

\subsection{Eco-Feedback System Architecture}

The study was enabled by the development of a novel eco-feedback system, BizWatts [43], which collects energy-use data through commercially available plug load power monitors. Each power monitor connects to standard North American $120 \mathrm{~V}$ outlets and wirelessly communicates a connected appliance's power information via $900 \mathrm{MHz}$ RF signal to an edge router that uploads data to a database via Ethernet connection. Time, location, real power (W), current (A), voltage (V), and power factor data were pushed through the router every 15 minutes to a database hosted on an Amazon Web Services server and managed by the People Power Company. BizWatts retrieved the energy-use information from the People Power server and periodically moved data to an independently hosted database, where it was stored and parsed to expedite data visualization loading. To minimize these load times, same day power and energy information was retrieved directly from the People Power server, while aggregated and preprocessed historical energy information was retrieved from the BizWatts server. While up to 12 appliances (e.g. computers, fans, space heaters) can be independently monitored for each user, in the study only the total energy-use of all connected appliances for each study participant was monitored - future studies will investigate if appliance data granularity impacts conservation behavior.

\subsection{Study Procedure}

Once energy monitors were installed at each workstation, baseline energy-use data was collected for 3 weeks from April $17^{\text {th }}$ to May $8^{\text {th }}$. The study commenced on May $9^{\text {th }}, 2013$ following an email to participants in Groups $A$ and $B$. The email announced the official launch of the study and included BizWatts login information as well as a link to a video tutorial describing how to use specific system features.

The study lasted for 9 weeks from May $9^{\text {th }}$ to July $9^{\text {th }}$, during which energy-use and clickstream data were collected for each participant. Additional emails were sent to participants in Groups A and $B$ on May $28^{\text {th }}$, June $17^{\text {th }}$, and June $30^{\text {th }}$ to update them about the energy saving actions that they can take and to remind them to visit the BizWatts web-based eco-feedback system. In these emails, participants in Group B also received information about energy conservation behavior and sustainability-oriented actions reported by other individuals in their organization. In addition to the emails, printed reminders to use the BizWatts system were also posted in hallways and common areas throughout the building. These reminders remained until the end of the study, when a final email was sent to announce the completion of the study. 
A total of ten individuals (one in Group A, nine in Group B) were removed from the analysis. Several individuals in Group B were removed due to an isolated network disruption which caused an edge router to stop reporting energy data for the majority of the study period. As individuals were assigned groups according to organizational and physical proximity, the disruption was locally contained and only impacted a subset of Group B. In addition, other individuals quit their organizations or relocated outside the study building during the course of the study and had to be removed.

\section{Data Analysis}

To control for externalities (e.g., weather, schedule variations, power outages) that could impact individual energy consumption trends over the duration of the study, all data analysis was conducted using a percent difference measure relative to the consumption of the control group, as defined in the following equation:

$$
\delta_{\text {period }}=\left(\mathrm{P}_{\text {period }}-\mathrm{C}_{\text {period }}\right) / \mathrm{C}_{\text {period }}
$$

The subscript 'period' specifies the range of days over which $\delta$ is calculated, $(\mathrm{P})$ is the average daily power draw of a user over the period and (C) is the average per capita daily power draw of the control group over the period. To determine if a study group's average level of energy consumption changed after gaining access to energy feedback, $\delta$ was calculated for each user's baseline and study periods. The distributions of $\delta$ values for each group's users were then tested for normality, after which appropriate statistical tests were selected to compare means between baseline and study periods. For normal distributions, a student paired t-test was used; otherwise, a Wilcoxon signed-rank test was used. A student paired t-test is a method for testing if two data sets that are each normally distributed are statistically distinct. If either of the data sets does not follow a normal distribution, then a more general non-parametric statistical test (Wilcoxon signed-rank test) must be used to determine if the means of the two data sets are statistically distinct. In the case of this energy efficiency study, if the distribution means are statistically distinct at a 95\% confidence level, it could be inferred that the feedback intervention may have changed the level of energy consumption for the target group.

In addition to monitoring individual and group-based energy-use data for analysis, BizWatts collected time-stamped user clickstream data to facilitate analysis of the frequency and types of interactions that users have with the system. Over the course of the study, clickstream data related to logins, page visits, graph views, and posts on the system were collected for each user. More detailed information about the full range of clickstream data collected by the BizWatts system can be found in [43]. General differences in the level of interaction among users in different groups were observed and are described in the following section.

\section{Results}

Figure 2 graphs the differences in energy consumption between participants in Groups $A$ and $B$ relative to the control group for each day from the start of the baseline period to the end of the study period. During the first 4 weeks of data collection (including the baseline period), there is 
little discernable separation between the energy consumption of Study Groups A and B. However, about 3 weeks after access to energy feedback was provided, a general trend in which Group $B$ begins to consistently consume less than Group A relative to the control group can be observed.

On average, individuals in the organizational network group consumed $13 \%$ less energy than the control group for each day after the start of the study. In addition to the observed trending separation, there was sudden spike in energy-use for both groups relative to the control group on May $21^{\text {st }}$ 2013. It was confirmed that an unusually large number of individuals in the control group were absent on that day, resulting in the spike.

After calculating $\delta$ values for users in each group over baseline and study periods, KolmogorovSmirnov tests were used to test for normality. The Kolmogorov-Smirnov test is a standard goodness-of-fit test that compares an empirical data set to any given statistical distribution. In this case, the set of $\delta$ values for each study group was compared to a normal distribution and tests revealed that the distributions of each group's $\delta$ values over baseline and study periods were not distinct from a normal distribution at a $95 \%$ confidence level. As a result, student paired t-tests were used to test for statistically significant differences between each group's baseline and study period energy consumption levels. Results from these tests are presented in Table 1.

At a 95\% confidence level, there was not enough evidence to reject the null hypothesis for Hypothesis 1 that there was no change in Group A's average individual energy consumption from the baseline to the study period, though the $\mathrm{p}$-value of 0.2324 may suggest weak evidence of an intervention effect that should be examined in future research with a larger number of participants. Alternately, the difference in the mean energy consumption from baseline to study period for Group $B$ was statistically significant (p-value $=0.02266$ ) enabling the rejection of the null hypothesis associated with Hypothesis 2 . This difference suggests that the ability to directly compare personal energy-use feedback with that of others may indeed motivate significant energy conservation among individuals. It should also be noted that although the difference in means for the individual feedback group is greater than for the organizational network feedback group, the variance of energy-use among members in the individual group was also greater, which explains why this larger difference was not statistically significant.

The results from the study are consistent with findings by Siero et al. [40], who found that comparative energy-use feedback between groups is more effective than individual feedback for motivating energy conservation actions. They also expand on the primary findings of Peschiera et al. [27], who observed similar impacts on energy-use among individuals exposed to social network energy-use data in a residential building. However, while these results are consistent with previous studies, the increasingly consistent separation of energy-use trends between the two study groups relative to the control group observed in Figure 2 suggests that the effects of feedback on energy-use differs between commercial and residential building occupants. Peschiera et al. found that residential building occupant energy-use was very elastic and would drastically decrease in the short-term following email notifications sent to study participants; 
Figure 2 suggests that energy conservation among commercial building occupants may be less elastic and more sustained in the long-term. To address this observation, post-hoc data analysis was conducted to determine if commercial building occupants exhibited any statistically significant short-term energy-use response-relapse patterns. To facilitate comparative analysis, the short-term response measurement periods were chosen to match those used in the study by Peschiera et al. [27], and include the first two weeks following the launch of the study and the 3 day periods following each email notification sent to participants. Results of this response analysis are presented in Table 2.

In contrast to the residential building study by Peschiera et al. [27], there were no consistent short-term energy conservation responses following email notifications among individuals with access to energy-use information of others in their organizational networks. While the organizational network group achieved significant energy-use reductions relative to baseline levels over the course of the entire study, the only short-term period in which a statistically significant reduction in energy-use was observed was the 3-day period following the second email notification, and this was only observed for the individual feedback group. This difference suggests that energy conservation habits form more easily among commercial building occupants exposed to organizational network feedback than among residential building occupants exposed to social network feedback, as energy-use behavior is less elastic in short-term periods following email based reminders.

In addition to monitoring the energy-use patterns of commercial building occupants, the BizWatts system allows individuals to self-report energy conservation and general sustainabilityoriented actions, enabling them to track their progress in adopting certain conservation strategies. With this additional information, initial energy-use analysis can be complemented by further investigating how the formation and adoption of energy conservation habits and interaction patterns with the eco-feedback system may differ between commercial and residential building occupants.

The number of reported actions by users in each study group, broken down by type of action, is presented in Table 3. The list of actions from which users could choose to report was decided on by building managers, who selected the specific actions to reflect what they believed to be relevant to building tenants. Over the course of the study, individuals in Study Group A reported a total of 43 actions, while those in Study Group B reported 81 actions. Total actions reported among individuals in Study Group B were significantly more for each category except for 'Common Lights', which referred to turning off overhead lighting when exiting a room. Turning off common overhead lighting and office equipment were the most popular self-reported actions among Study Group A individuals, while taking public transportation and using the stairs (instead of the elevator) were the most popular actions among Study Group B individuals.

A graphical representation of the number of actions reported over time can be observed in Figure 3. In contrast to individual energy-use patterns which did not exhibit significant short-term changes in response to email notifications, the number of self-reported actions seemed to spike 
following reminders. Users reported the most number of actions in the first two weeks of the study launch, with local maxima observed on dates following email notifications sent on May $29^{\text {th }}$ and July $1^{\text {st }}$. These patterns suggest that email notifications are useful for reminding commercial building occupants to interact with eco-feedback systems and to report conservation actions.

Further evidence that email notifications effectively spurred increased user interaction with the eco-feedback system can be observed in Figure 4, where user logins over time are plotted.

Exhibiting a similar pattern to the number of reported actions over time, users logged into the eco-feedback system with decreasing frequency over the course of the study. Furthermore, the system experienced the largest number of logins in the first 2 weeks of the study launch, with short-term spikes in usage corresponding to email notifications sent on May $29^{\text {th }}$ and July $1^{\text {st }}$. Among all study participants, $42 \%$ interacted with the eco-feedback system: approximately $40 \%$ of participants in Study Group A and $45 \%$ in Study Group B. Study Group B participants who logged into the system averaged about 4.23 logins per person, while those in Study Group A only averaged about 1.74 logins per person, suggesting that connecting individuals over organizational networks within an eco-feedback system can motivate them to use the system for frequently and report more actions than if they could only access personal information.

\section{Discussion}

Findings from this commercial building energy efficiency study provide many new insights that expand an understanding of how commercial building occupants utilize personalized individual and group-based energy feedback. Consistent with previous research studies in settings where building occupants had no direct financial incentive to conserve energy [27], it was observed that commercial building occupants who could directly compare current and historical energy-use patterns with others conserved a statistically significant amount of energy relative to a control group and baseline period. In this study, the ability to compare energy-use information with others was limited to the structure of pre-existing organizational networks within the commercial building, thus providing empirical support for previous survey-based findings that organizational culture is an important factor for motivating energy conservation [46]. However, while organizationally connected commercial building occupants did conserve statistically significant amounts of energy, they did not exhibit the same response-relapse patterns as residential building occupants [27]. Energy savings were steady through the duration of the study with no sudden significant short-term decreases in energy consumption following email notifications, suggesting that energy conservation behavior in commercial buildings may be more steady and persistent than in residential buildings.

Also consistent with previous building eco-feedback studies [27, 45], it was observed that isolated personal energy-use feedback was not sufficient to significantly impact energy conservation behavior. The inability for users to interact with others in their organizational networks also directly impacted the frequency with which users logged into the eco-feedback system and reported conservation actions. Individuals in the organizational network group 
logged in about 2.5 times more often than those in the individual feedback group, supporting results from another residential eco-feedback study, in which users with access to normative energy-use comparisons interacted with the feedback system nearly 5 times more than users with access only to personal feedback [25]. Large differences in the number of reported conservation actions, which represent significant energy saving opportunities beyond desktop appliance management, were also observed. Individuals in the organizational network feedback group reported nearly twice as many conservation actions as participants in the individual feedback group, thereby supporting findings by Siero et al. [40]. Furthermore, one of the most frequently reported actions by the organizational network group was taking the stairs instead of the elevator. As individuals in this group were located on the $4^{\text {th }}$ and $5^{\text {th }}$ floors of the study building, this represents the adoption and/or reporting of an action that requires non-trivial physical effort and corresponds to potentially significant energy savings not captured by the energy monitoring system.

On a general level, this study confirms that when presented with socially and organizationally contextualized energy-use information, commercial building occupants are capable of reducing energy waste attributed to appliances that are often left powered on in non-residential buildings

[48] and achieving the potential energy-savings predicted by previous simulation models through behavioral means [37]. These findings are especially relevant considering that this study was conducted in a LEED certified building, thus demonstrating that significant energy savings can be achieved through behavioral means in already energy efficient buildings. By empowering employees and commercial building occupants with energy-use feedback, significant energy savings can be achieved without significant financial expenditures. Modular, low-cost ecofeedback systems therefore stand to significantly benefit small businesses that aspire to costeffectively reduce operational costs through behavior based campaigns. As small businesses represent approximately 34 billion sq. ft. of commercial real estate in the United States [49], large-scale energy savings and emissions reductions can be achieved by developing and disseminating customizable, low-cost eco-feedback technologies.

\section{Limitations}

While a statistically significant reduction in energy consumption among individuals exposed to organizational network energy feedback was observed, the study was limited to a single, multitenant commercial building and could have benefitted from a larger sample size. Commercial building occupants who all belong to a single, large corporation may interact differently than those in multiple, smaller organizations. Furthermore, this study was limited in its sample size and data collection was constrained to a 12 week period. While statistically significant results indicated that organizational feedback can indeed impact energy consumption in a commercial building, future studies should include an expanded sample size and be conducted over a longer period. In this way, longitudinal effects in various contexts can be better understood.

In this study, all organizations that participated possessed an environmental focus and therefore results may not translate to organizations that lack an explicit pro-environmental culture. Nonetheless, the results of the study show that even organizations with pre-existing pro- 
environmental cultures can benefit from energy feedback. While the system was able to monitor individual level energy-use, the study could have benefited from the added capability of confirming the conservation actions reported by users that fell beyond the scope of the monitoring system. In this way, additional energy savings could be quantified.

\section{Future Research}

A natural extension of this study would be to examine how various organization network structures (hierarchical, flat, distribution) impact energy conservation. In this study, no organizational roles were defined or emphasized in the system, and so it was not possible to track how the effect of energy-use information varies with organizational role or position. Furthermore, as individuals in organizations often form informal social networks independent of their organizational networks, future research should examine how individuals connected to friends rather than co-workers might change their energy consumption behavior. Once it is better understood how various network effects impact energy conservation, eco-feedback systems can be better designed to accommodate these effects in order to maximize potential energy savings among users.

\section{Conclusion}

It has been demonstrated that providing commercial building occupants with individual energy feedback does not necessarily motivate them to conserve energy. However, providing individuals with access to energy-use information of others in their organizational network can result in significant energy savings. In addition, while the number of interactions with the eco-feedback system decreased over the course of the study, connected commercial building occupants maintained energy efficient behavior and did not exhibit the same response-relapse patterns as residential building occupants after receiving email notifications. Building occupants connected over the eco-feedback system also logged in more frequently and reported more conservation actions than individuals who could only access their own energy-use information, resulting in additional energy savings that the system could not directly capture. The study results imply that future commercial building eco-feedback systems should be designed to connect individuals and groups in organizations, in order to benefit from increased user-system interactions and to realize significant energy savings. As an understanding of how network connections impact energy conservation continues to develop, eco-feedback system designs should continue to be improved to maximize their potential to induce energy savings among commercial building occupants.

\section{Acknowledgements}

This material is based upon work supported by the Department of Energy Building Technologies Program and the National Science Foundation under Grant No. 1142379. Any opinions, findings, and conclusions or recommendations expressed in this material are those of the authors and do not necessarily reflect the views of the Department of Energy or the National Science Foundation. The authors would like to thank the Alliance for Sustainable Colorado for hosting the study and helping with management and study administration. 


\section{References}

[1] Environmental Protection Agency (2013) "Buildings and their Impact on the Environment: A Statistical Summary" $<$ http://www.epa.gov/greenbuilding/pubs/gbstats.pdf>(Sep. 1, 2013)

[2] Energy Information Agency (2009) "Emissions of Greenhouse Gases in the United States Report" <http://www.eia.gov/environment/emissions/ghg_report/pdf/tbl3.pdf $>$ (Sep. 1, 2013)

[3] US Green Buildings Council (2007) "Buildings and Climate Change Document" $<$ www.usgbc.org/ShowFile.aspx?DocumentID=5033> (Sep. 1, 2013)

[4] United States White House (2012) "Administration Announces New Tools to Help Consumers Manage Electricity Use and Shrink Bills" $<\mathrm{http} / / / \mathrm{www}$.whitehouse.gov/administration/eop/ostp/pressroom/01182012> (Oct 1,2013)

[5] US Department of Energy (2010) "Buildings Energy Data Book" <http://buildingsdatabook.eere.energy.gov/> (Sep. 1, 2012)

[6] US Green Buildings Council (2013) "LEED Rating Systems" $<$ http://www.usgbc.org/leed/certification> (Oct. 16, 2013)

[7] RESNET (2013) "Mortgage Industry National Home Energy Rating Standards" $<$ http://www.resnet.us/professional/standards/mortgage> (Oct. 16, 2013)

[8] US Environmental Protection Agency (2013) "Energy Star Program" $<$ http://www.energystar.gov/> (Oct. 16, 2013)

[9] US Green Button Initiative (2013) "About Green Button" $<$ http://www.greenbuttondata.org/greenabout.html > (Oct. 16, 2013)

[10] International Organizations for Standardization (2013) "ISO 50001 - Energy Management" <http://www.iso.org/iso/home/standards/managementstandards/iso50001.htm> (Oct. 16, 2013)

[11] Seligman C, Darley JM, Becker LJ. Behavioral approaches to residential energy conservation. Energy and Buildings 1978; 1(3), 325-337.

[12] Becker, L. (1978). "Joint effect of feedback and goal setting on performance: A field study of residential energy conservation.” Journal of Applied Psychology, 63(4), 428433.

[13] McCalley, L. ., and Midden, C. J. . (2002). "Energy conservation through productintegrated feedback: The roles of goal-setting and social orientation." Journal of Economic Psychology, 23(5), 589-603.

[14] Abrahamse W, Steg L, Vlek C, Rothengatter T. The effect of tailored information, goal setting, and tailored feedback on household energy use, energy-related behaviors, and behavioral antecedents. Journal of Environmental Psychology 2007; 27(4), 265-276. 
[15] Nolan JM, Schultz PW, Cialdini RB, Goldstein NJ, Griskevicius V. Normative Social Influence is Underdetected. Personality and Social Psychology Bulletin 2008; 34(7), 913-923.

[16] Iyer M, Kempton W, Payne C. Comparison groups on bills: Automated, personalized, energy information. Energy and Buildings 2006; 38: 988-996.

[17] Schultz, P. W., Nolan, J. M., Cialdini, R. B., Goldstein, N. J., and Griskevicius, V. (2007). "The constructive, destructive, and reconstructive power of social norms." Psychological science, 18(5), 429-34.

[18] OPower. (2011). “oPower.”〈www.opower.com〉 (Jul. 13, 2011).

[19] ComEd. (2011). "Home | ComEd - An Exelon Company." 〈www.comed.com〉 (Jul. 13, 2011).

[20] Allcott H. Social norms and energy conservation. Journal of Public Economics 2011; 95(9-10), 1082-1095.

[21] Gulbinas R, Jain R, Taylor JE, Peschiera G, Golparvar-Fard M. Network EcoInformatics: Development of a Social Eco-Feedback System to Drive Energy Efficiency in Residential Buildings. ASCE Journal of Computing in Civil Engineering 2013; 10.1061: 1943-5487

[22] Froehlich J, Findlater L, Landay J. The design of eco-feedback technology. Proceedings of the 28th international conference on Human factors in computing systems; 2010; Atlanta, USA: ACM; 2010. p. 1999-2008.

[23] Ueno T, Sano F, Saeki O, Tsuji K. Effectiveness of an energy-consumption information system on energy savings in residential houses based on monitored data. Applied Energy 2006; 83(2), 166-183.

[24] Fischer C. Feedback on household electricity consumption: a tool saving energy? Energy Efficiency 2008; 1(1), 79-104.

[25] Foster D, Lawson S, Blythe M, Cairns P. Wattsup?: Motivating reductions in domestic energy consumption using social networks. Proceedings of the 6th Nordic Conference on Human-Computer Interaction: Extending Boundaries; 2012; Reykjavic, Iceland: ACM; 2012. p. 178-187.

[26] Petkov P, Köbler F, Foth M, Krcmar H. Motivating domestic energy conservation through comparative, community-based feedback in mobile and social media. Proceedings of the 5th International Conference on Communities and Technologies; 2011; Brisbane, Australia: ACM 2011. p. 21-30.

[27] Peschiera G, Taylor JE, Siegel JA. Response-relapse patterns of building occupant electricity consumption following exposure to personal, contextualized and occupant peer network utilization data. Energy and Buildings 2010; 42(8), 1329-1336.

[28] Petersen JE, Shunturov V, Janda K, Platt G, Weinberger K. Dormitory residents reduce electricity consumption when exposed to real-time visual feedback and incentives. International Journal of Sustainability in Higher Education 2007; 8(1), 16-33. 
[29] Jain R, Taylor J, Culligan P. Investigating the Impact Eco-Feedback Information Representation has on Building Occupant Energy Consumption Behavior and Savings. Energy and Buildings 2013; 64: 408-414.

[30] Peschiera G, Taylor JE. The Impact of Peer Network Position on Electricity Consumption in Building Occupant Networks Utilizing Energy Feedback Systems. Energy and Buildings 2012; 49: 584-590.

[31] Jain R, Gulbinas R, Taylor JE, Culligan P. Can Social Influence Drive Energy Savings? Detecting the Impact of Social Influence on the Energy Consumption Behavior of Networked Users Exposed to Normative Eco-feedback. Energy and Buildings 2013; 66: 119-127.

[32] Grevet C, Mankoff J, Anderson SD. Design and evaluation of a social visualization aimed at encouraging sustainable behavior. Proceedings of 43rd Hawaii International Conference on System Sciences 2010; IEEE Computer Society, 1-8.

[33] Jain RK, Taylor JE, Peschiera G. Assessing eco-feedback interface usage and design to drive energy efficiency in buildings. Energy and Buildings 2012; 48, 8-17.

[34] Chen V, Delmas M, Kaiser W. Real-time appliance-level electricity use feedback system: How to engage users? Energy and Buildings 2014; 70:455-462.

[35] Wood G, Newborough M. Energy-use information transfer for intelligent homes: Enabling energy conservation with central and local displays. Energy and Buildings 2007; 39: 495-503.

[36] Dietz T, Gardner GT, Gilligan J, Stern PC, Vandenbergh MP. Household actions can provide a behavioral wedge to rapidly reduce US carbon emissions. Proceedings of the National Academy of Sciences 2009; 106(44), 18452-18456.

[37] Azar E, Menassa C. Agent-based modeling of occupants and their impact on energy use in commercial buildings. Journal of Computing in Civil Engineering 2011; 26.4: 506518.

[38] Azar E, Menassa C. A comprehensive analysis of the impact of occupancy parameters in energy simulation of office buildings. Energy and Buildings 2012; 55: 841-853.

[39] Carrico AR, Riemer M. Motivating energy conservation in the workplace: An evaluation of the use of group-level feedback and peer education. Journal of Environmental Psychology 2011; 31, 1-13.

[40] Siero FW, Bakker AB, Dekker GB, Van Den Burg MTC. Changing organizational energy consumption behaviour through comparative feedback. Journal of Environmental Psychology 1996; 16(3), 235-246.

[41] United States Postal Service (2012) "Postal Service Saves Millions in Energy Costs" <http://about.usps.com/news/national-releases/2012/pr12_097.htm> (Nov. 13, 2012)

[42] Starbucks (2012) "Energy Conservation" <http://www.starbucks.com/responsibility/environment/energy> (Oct. 1, 2013) 
[43] Gulbinas R, Jain R, Taylor J. BizWatts: A Commercial Building Eco-Feedback System for Quantifying Organizational and Social Network Effects on Conservation. Proceedings of the 2013 International Conference on Applied Energy; 2013; Pretoria, South Africa: July 1-4, 2013.

[44] Randazzo KV, Peters JS. Reconsidering What We Measure: A White Paper. Opinion Dynamics Corporation, Waltham, MA; 2011.

[45] Murtagh N, Nati M, Headley WR, Gatersleben B, Gluhak A, Imran M, Uzzell D. Individual energy use and feedback in an office setting: A field trial. Energy Policy 2013; 62: 717-728.

[46] Zhang Y, Wang Z, Zhou G. Antecedents of employee electricity saving behavior in organizations: An empirical study based on norm activation model. Energy Policy 2013; 62: 1120-1127.

[47] Coleman M, Irvine K, Lemon M, Shao L. Promoting behavior change through personalized energy feedback in offices. Building Research and Information 2013; 41:6, 637-651.

[48] Marans RW, Edelstein JY. The human dimension of energy conservation and sustainability: A case study of the University of Michigan's energy conservation program. International Journal of Sustainability in Higher Education 2010; 11:1, 6 - 18.

[49] United States Small Business Administration (2013) "Small Business Trends" $<\mathrm{http}: / / \mathrm{www}$. sba.gov/content/small-business-trends> (Oct. 1, 2013) 
Figure 1: Alliance for Sustainable Colorado

Figure 2: Percent difference $(\delta)$ values for Group A (Organization Network Feedback Group) and B (Individual Feedback Group) users over baseline to study periods

Figure 3: Number of Actions by Date

Figure 4: System Logins by Date 
Table 1: Group A and B performance during study period relative to baseline period

\begin{tabular}{|c|c|c|c|c|}
\hline \multicolumn{5}{|c|}{ Baseline to Study Period } \\
\hline \multirow[t]{2}{*}{ Study Group } & \multicolumn{2}{|c|}{ 95\% Confidence Interval } & \multirow[t]{2}{*}{ Mean of Differences } & \multirow[t]{2}{*}{$\mathrm{p}$} \\
\hline & Lower Bound & Upper Bound & & \\
\hline Organizational Network Feedback & 1.053 & 12.793 & 6.923 & $0.02266^{*}$ \\
\hline Individual Feedback & -7.61 & 30.34 & 11.3656 & 0.2324 \\
\hline
\end{tabular}

*Statistically significant $(\mathrm{p}<0.05)$

Table 2: Responses to notification emails relative to baseline periods

\begin{tabular}{|c|c|c|c|c|}
\hline \multicolumn{5}{|c|}{ Organizational Network Group } \\
\hline \multirow[t]{2}{*}{ Period } & \multicolumn{2}{|c|}{ 95\% Confidence Interval } & \multirow[t]{2}{*}{ Mean of Differences } & \multirow[t]{2}{*}{$\mathrm{p}$} \\
\hline & Lower Bound & Upper Bound & & \\
\hline Whole Study & 1.053 & 12.793 & 6.923 & $0.02266^{*}$ \\
\hline Launch (2 Weeks) & -11.153 & 10.086 & -0.533 & 0.9186 \\
\hline 5/29 Email (3 days) & -5.641 & 29.96 & 12.16 & 0.1721 \\
\hline 6/18 Email (3 Days) & -16.833 & 12.477 & -2.178 & 0.7621 \\
\hline 7/1 Email (3 Days) & -17.59 & 43.408 & 12.908 & 0.3917 \\
\hline \multicolumn{5}{|c|}{ Individual Feedback Group } \\
\hline \multirow[t]{2}{*}{ Period } & \multicolumn{2}{|c|}{ 95\% Confidence Interval } & Mean of Differences & $\mathrm{p}$ \\
\hline & Lower Bound & Upper Bound & & \\
\hline Whole Study & -7.61 & 30.34 & 11.3656 & 0.2324 \\
\hline Launch (2 Weeks) & -3.432 & 20.125 & 8.346 & 0.1593 \\
\hline 5/29 Email (3 days) & 3.506 & 40.319 & 21.912 & $0.02097 *$ \\
\hline 6/18 Email (3 Days) & -15.511 & 11.831 & -1.84 & 0.7861 \\
\hline 7/1 Email (3 Days) & -60.01 & 16.838 & -21.584 & 0.2618 \\
\hline
\end{tabular}

*Statistically significant $(\mathrm{p}<0.05)$

Table 3: Self-Reported

Conservation Actions

\begin{tabular}{l|r}
\hline \multicolumn{2}{c}{ Actions By Type } \\
\hline Individual Only & \# Actions \\
\hline No Meat & 3 \\
Stairs & 5 \\
Bath Lights & 6 \\
Commute & 7 \\
Equipment Off & 10 \\
Common Lights & 12 \\
\hline Organizational Network & \# Actions \\
\hline Common Lights & 7 \\
No Meat & 9 \\
Bath Lights & 9 \\
Equipment Off & 17 \\
Stairs & 19 \\
Commute & 20
\end{tabular}




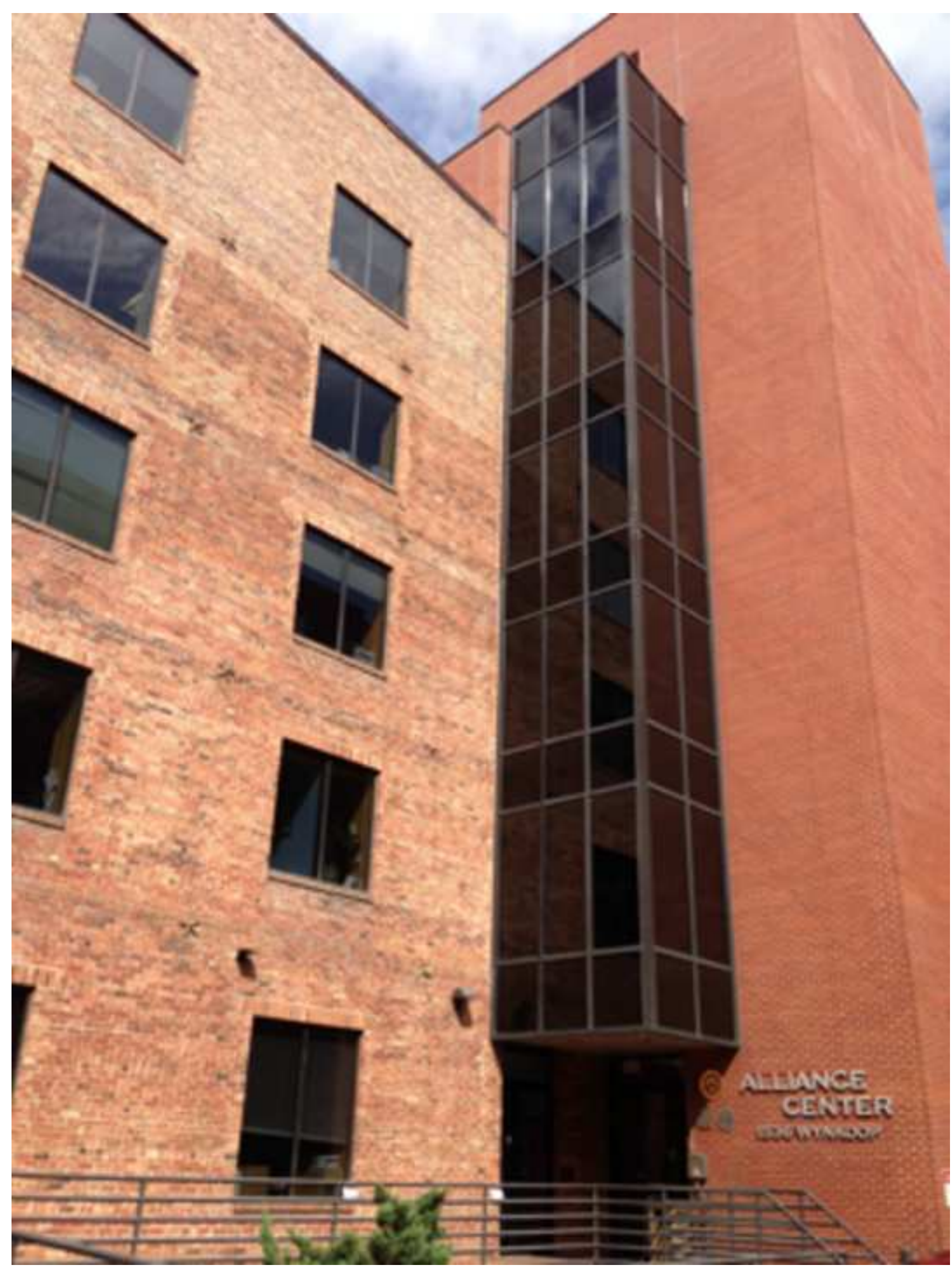

Figure

Figure .

( 


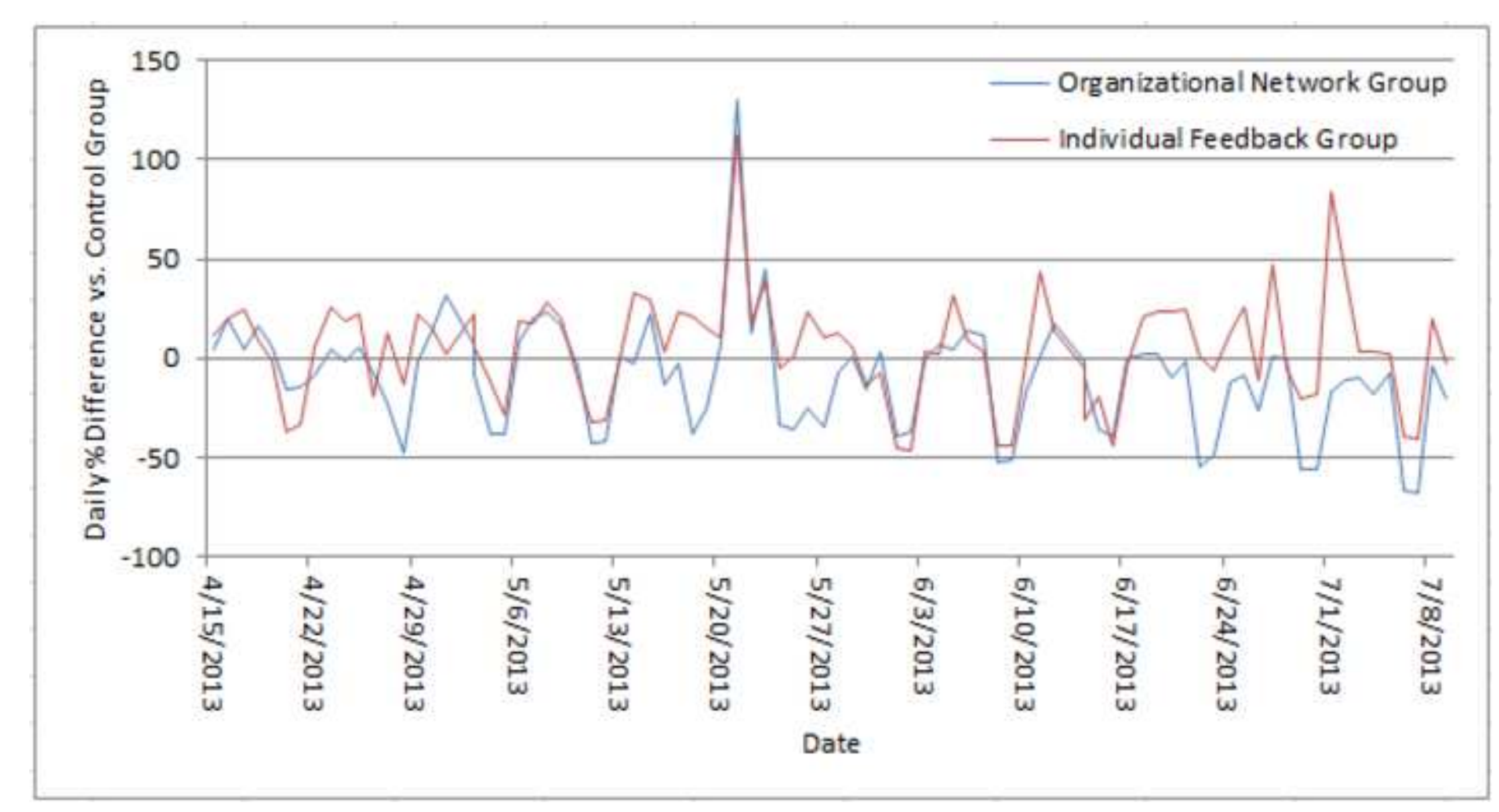

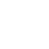




\section{Number of Actions by Date}

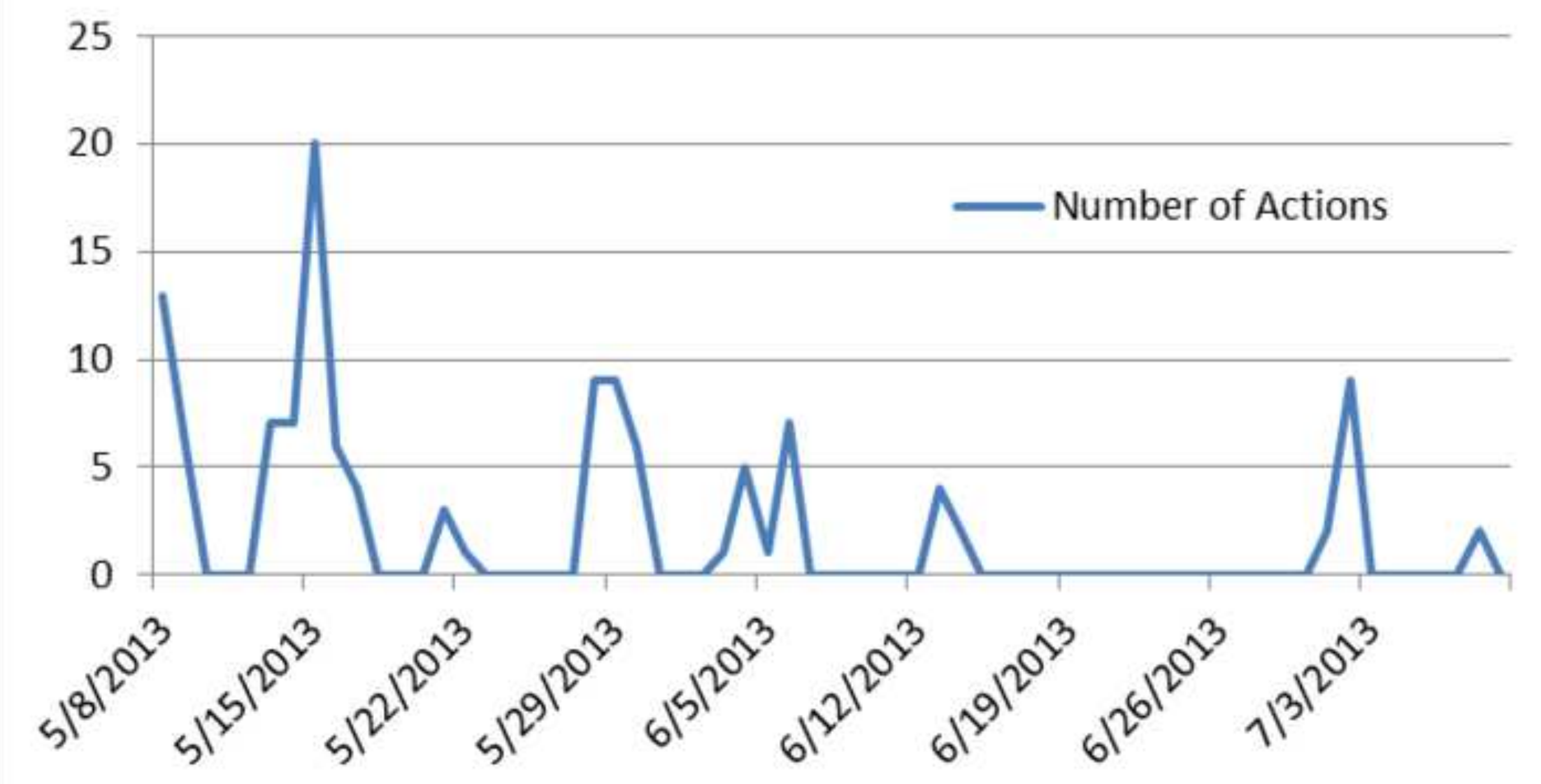




\section{Logins by Date}

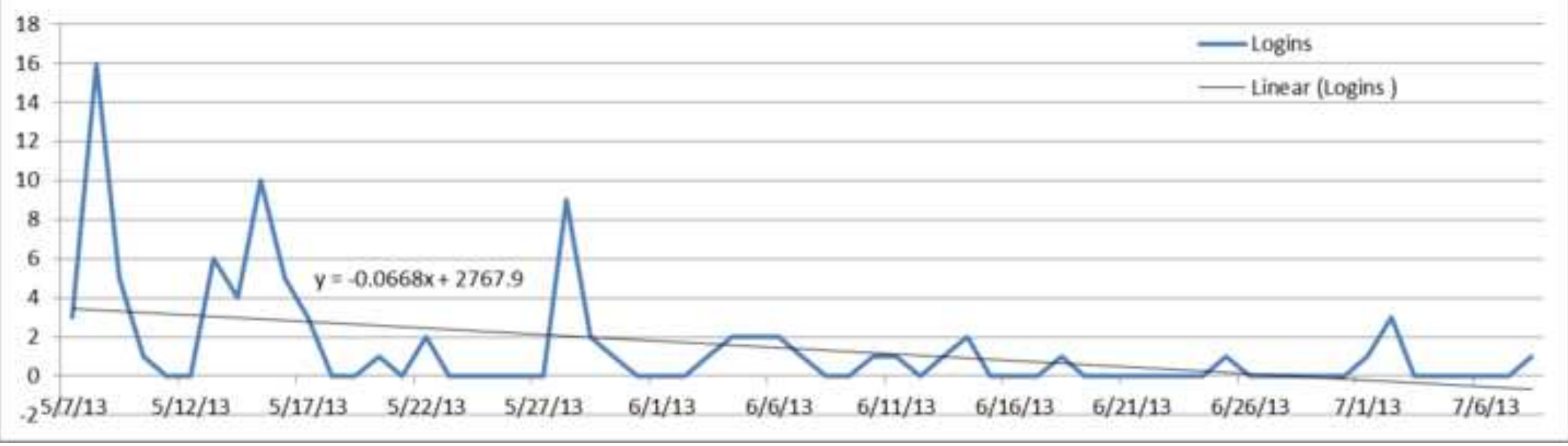

